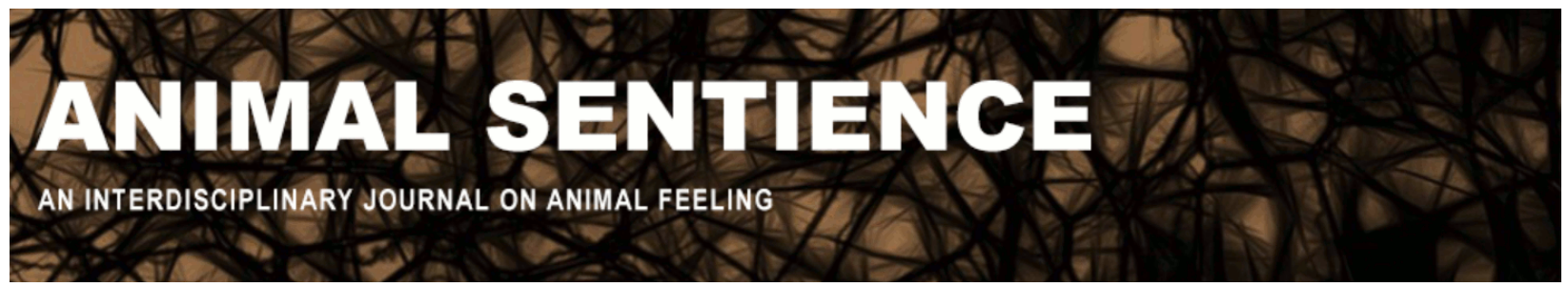

van Kleef, Gerben A. (2018) Emotional reactions in non-human animals and social-functional theories of emotion. Animal Sentience 22(12)

DOI: $10.51291 / 2377-7478.1342$

Date of submission: 2018-06-06

Date of acceptance: 2018-06-09

(c) $\underset{\mathrm{EY}}{\mathrm{C}}$

This article has appeared in the journal Animal

Sentience, a peer-reviewed journal on animal

cognition and feeling. It has been made open access,

free for all, by WellBeing International and deposited

in the WBI Studies Repository. For more information,

please contact

wbisr-info@wellbeingintl.org.

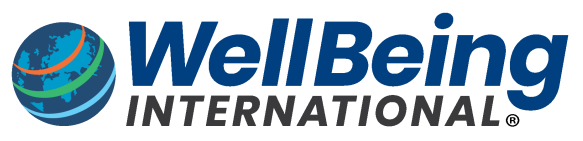

SOLUTIONS FOR PEOPLE, ANIMALS AND ENVIRONMENT 


\title{
Emotional reactions in non-human animals and social-functional theories of emotion
}

Commentary on Cook et al. on Dog Jealousy

\author{
Gerben A. van Kleef \\ University of Amsterdam
}

\begin{abstract}
The debate about animal emotions relies heavily on empirical evidence, which is often open to multiple interpretations. This ambiguity allows researchers at either end of the spectrum to perceive support for their positions in study results. Thus, evidence reported by Cook and colleagues (2018) - that dogs' trait aggression is associated with their amygdala activation when watching their caregivers feed a fake dog - may be interpreted by some as neural evidence for jealousy in dogs and by others as an artefact of the study design. I argue that the discussion should be complemented with a greater consideration of theoretical arguments about the (social) functions of emotions. Theory and research on the intrapersonal and interpersonal effects of emotions are consistent with the hypothesis that various non-human social animals can experience and communicate emotions, although the labeling of these emotions is not selfevident.
\end{abstract}

Gerben A. van Kleef is professor of social psychology at the University of Amsterdam. His main research themes revolve around the social effects of emotions, the antecedents and consequences of power and hierarchy, and the social dynamics of norm violation versus norm adherence.

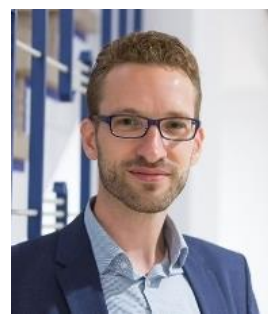

Website

Whether animals have emotions has been debated for more than a century, dating back at least to Darwin's seminal work The expression of the emotions in man and animals (1872). The topic continues to divide scientists to this day. Some scholars point to studies that have provided evidence of emotion in a wide variety of non-human species; others warn that projection of human-like emotional states onto non-human animals constitutes a form of anthropomorphism. The problem is that empirical demonstrations of animal emotions are elusive because the data of most (if not all) studies tend to be open to multiple interpretations. I propose that this problem can be alleviated by complementing the debate over empirical findings with a more thorough consideration of theory.

My point is illustrated by Cook, Prichard, Spivak, and Berns's (2018) study of emotional responses in dogs. Cook and colleagues report evidence that temperamental dogs show increased amygdala activation when watching food being given to a (fake) rival dog rather than to themselves (or an inanimate bucket); they interpret this as evidence for a form of jealousy. As is clear from some of the commentaries on their target article, other scholars are reluctant to accept the results as evidence of jealousy in dogs, mostly based on inherent limitations of the study 
design. What remains largely unaddressed is the broader theoretical state of the art in affective science, in particular in the realm of social-functional theories of emotion. This work is relevant to the current discussion; and as I will argue here, it is compatible with the hypothesis that various non-human animals have the capacity for emotional experience and emotional communication.

According to social-functional theories, emotions evolved because they serve critical functions for individuals (Keltner \& Haidt, 1999; Van Kleef, 2016). Two broad and mutually complementary theoretical perspectives can be distinguished: the intrapersonal perspective and the interpersonal perspective. According to the intrapersonal perspective, emotional experiences alert organisms to relevant changes in the environment and help them prepare for adaptive behavioral responses (Farb, Chapman, \& Anderson, 2013; Frijda, 1986). According to the complementary interpersonal perspective, emotional expressions serve social-signaling functions that support communication and behavioral coordination between individuals (Van Kleef, 2009).

If we accept that emotions subserve such critical functions in humans nowadays, despite the fact that humans have developed intricate systems of language to facilitate complex communication and coordination, it is difficult to see why non-human animals who ostensibly have much less sophisticated communicative systems at their disposal would not benefit from similar intrapersonal and interpersonal emotional processes. Indeed, consistent with the assumption of phylogenetic continuity of the emotion system (Darwin, 1872), the major brain areas that have been implicated in emotional processes in humans (which are evolutionarily older than the brain areas involved in speech) are in place in many non-human animals as well. Several studies suggest similar functionality of these brain regions in humans and various non-human species (see e.g., Cook et al., 2018).

In keeping with these theoretical considerations, empirical research at the intrapersonal level of analysis suggests that various non-human animals experience "basic" emotions akin to the basic emotions in humans and that these emotions drive their behavior in analogous ways. Besides the obvious case of fear, there is evidence that non-human primates as well as dogs experience negative emotions in response to reward inequity, which produce behavioral patterns akin to human anger (Brosnan \& DeWaal, 2003; Range, Horn, Virányi, \& Huber, 2009; Range, Leitner, \& Virányi, 2012). Moreover, research at the interpersonal level of analysis indicates that, like humans, non-human primates use their conspecifics' emotional expressions to inform their own behavior. For example, rhesus monkeys witnessing expressions of fear in another monkey who was anticipating an electrical shock quickly learned to switch a lever that eliminated the shock (Mirsky, Miller, \& Murphy, 1958). In other studies, chimpanzees, bonobos, gorillas, and orangutans preferred the hidden contents of a box to which the (human) experimenter had reacted with a smile rather than with disgust. These studies indicate that non-human primates have the capacity to use others' emotional expressions to determine their own course of action.

Although I believe it is highly plausible for theoretical reasons that non-human animals such as apes, monkeys, and dogs are capable of emotional experience and emotional communication, this is not to say that non-human animals exhibit the full range of emotions known to humans, including intricate and multi-faceted emotions such as jealousy. We must be careful not to overinterpret the available empirical evidence. Cook et al.'s results indicate that dogs with a predisposition toward dog-dog aggression show increased arousal (as reflected in amygdala activation) when their caregivers feed a (fake) rival dog. This response pattern can be understood through a functional lens; but whether the arousal can be labeled "jealousy" remains to be seen. 


\section{References}

Brosnan, S. F., \& De Waal, F. B. (2003). Monkeys reject unequal pay. Nature, 425, 297-299.

Buttelmann, D., Call, J., \& Tomasello, M. (2009). Do great apes use emotional expressions to infer desires? Developmental Science, 12, 688-698.

Cook, P., Prichard, A., Spivak, M., \& Berns, G. S. (2018). Jealousy in dogs? Evidence from brain imaging. Animal Sentience 22(1).

Darwin, C. (1872). The expression of the emotions in man and animals (3rd ed.). London, UK: HarperCollins.

Farb, N. A., Chapman, H. A., \& Anderson, A. K. (2013). Emotions: Form follows function. Current Opinion in Neurobiology, 23, 393-398.

Frijda, N. H. (1986). The emotions. Cambridge, UK: Cambridge University Press.

Keltner, D., \& Haidt, J. (1999). Social functions of emotions at four levels of analysis. Cognition \& Emotion, 13, 505-521.

Mirsky, I. A., Miller, R. E., \& Murphy, J. V. (1958). The communication of affect in rhesus monkeys: I. An experimental method. Journal of the American Psychoanalytic Association, 6 , 433-441.

Range, F., Horn, L., Virányi, Z., \& Huber, L. (2009). The absence of reward induces inequity aversion in dogs. Proceedings of the National Academy of Sciences, 106, 340-345.

Range, F., Leitner, K., \& Virányi, Z. (2012). The influence of the relationship and motivation on inequity aversion in dogs. Social Justice Research, 25, 170-194.

Van Kleef, G. A. (2009). How emotions regulate social life: The emotions as social information (EASI) model. Current Directions in Psychological Science, 18, 184-188.

Van Kleef, G. A. (2016). The interpersonal dynamics of emotion: Toward an integrative theory of emotions as social information. Cambridge, UK: Cambridge University Press. 


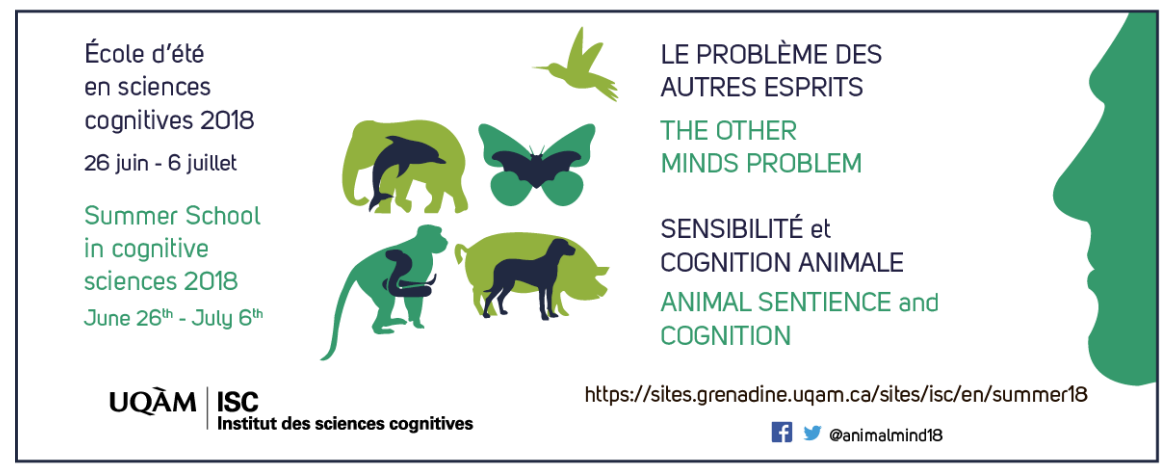

ISC 2018 Summer School in Cognitive Sciences June 26 - July 6, 2018 Montreal (Canada) The Other Minds
Problem: Animal
Sentience and Cognition

Overview. Since Descartes, philosophers know there is no way to know for sure what — or whether — others feel (not even if they tell you). Science, however, is not about certainty but about probability and evidence. The 7.5 billion individual members of the human species can tell us what they are feeling. But there are 9 million other species on the planet $(20$ quintillion individuals), from elephants to jellyfish, with which humans share biological and cognitive ancestry, but not one other species can speak: Which of them can feel — and what do they feel? Their human spokespersons - the comparative psychologists, ethologists, evolutionists, and cognitive neurobiologists who are the world's leading experts in "mindreading" other species - will provide a sweeping panorama of what it feels like to be an elephant, ape, whale, cow, pig, dog, chicken, bat, fish, lizard, lobster, snail: This growing body of facts about nonhuman sentience has profound implications not only for our understanding of human cognition, but for our treatment of other sentient species.

|Gregory Berns: Decoding the Dog's Mind with Awake

Neuroimaging

Gordon Burghardt: Probing the Umwelt of Reptiles

Jon Sakata: Audience Effects on Communication Signals

PANEL 1: Reptiles, Birds and Mammals

WORKSHOP 1: Kristin Andrews: The "Other" Problems: Mind,

Behavior, and Agency

Sarah Brosnan: How Do Primates Feel About Their Social

Partners?

Alexander Ophir: The Cognitive Ecology of Monogamy

Michael Hendricks: Integrating Action and Perception in a Small

Nervous System

PANEL 2: Primates, Voles and Worms

WORKSHOP 2: Jonathan Birch: Animal Sentience and the

Precautionary Principle

Malcolm Maclver: How Sentience Changed After Fish Invaded

Land 385 Million Years Ago

Sarah Woolley: Neural Mechanisms of Preference in Female

Songbird

Simon Reader: Animal Social Learning: Implications for

Understanding Others

PANEL 3: Sea to Land to Air

WORKSHOP 3: Steven M. Wise: Nonhuman Personhood

Tomoko Ohyama: Action Selection in a Small Brain (Drosophila

Maggot)

Mike Ryan: "Crazy Love": Nonlinearity and Irrationality in Mate

Choice

Louis Lefebvre: Animal Innovation: From Ecology to

Neurotransmitters

PANEL 4: Maggots, Frogs and Birds: Flexibility Evolving

SPECIAL EVENT: Mario Cyr: Polar Bears

Colin Chapman: Why Do We Want to Think People Are

Different?

Vladimir Pradosudov: Chickadee Spatial Cognition

Jonathan Balcombe: The Sentient World of Fishes

PANEL 5: Similarities and Differences

WORKSHOP 5 (part 1): Gary Comstock: A Cow's Concept of

Her Future

WORKSHOP 5 (part 2): Jean-Jacques Kona-Boun: Physical

and Mental Risks to Cattle and Horses in Rodeos
Joshua Plotnik: Thoughtful Trunks: Application of Elephant Cognition for Elephant Conservation

Lori Marino: Who Are Dolphins?

Larry Young: The Neurobiology of Social Bonding, Empathy and Social Loss in Monogamous Voles

Panel 6: Mammals All, Great and Small

WORKSHOP 6: Lori Marino: The Inconvenient Truth About

Thinking Chickens

Andrew Adamatzky: Slime Mould: Cognition Through

Computation

Frantisek Baluska \& Stefano Mancuso: What a Plant Knows and Perceives

Arthur Reber: $\mathrm{A}$ Novel Theory of the Origin of Mind:

Conversations With a Caterpillar and a Bacterium

PANEL 7: Microbes, Molds and Plants

WORKSHOP 7: Suzanne Held \& Michael Mendl: Pig Cognition and Why It Matters

James Simmons: What Is It Like To Be A Bat?

Debbie Kelly: Spatial Cognition in Food-Storing

Steve Phelps: Social Cognition Across Species

PANEL 8: Social Space

WORKSHOP 8: To be announced

Lars Chittka: The Mind of the Bee

Reuven Dukas: Insect Emotions: Mechanisms and Evolutionary Biology

Adam Shriver: Do Human Lesion Studies Tell Us the Cortex is

Required for Pain Experiences?

PANEL 9: The Invertebrate Mind

WORKSHOP 9: Delcianna Winders: Nonhuman Animals in

Sport and Entertainment

Carel ten Cate: Avian Capacity for Categorization and

Abstraction

Jennifer Mather: Do Squid Have a Sense of Self?

Steve Chang: Neurobiology of Monkeys Thinking About Other Monkeys

PANEL 10: Others in Mind

WORKSHOP 10: The Legal Status of Sentient Nonhuman

Species 